\title{
The Change of National Exam System from Paper- Based Test into Computer-Based Test
}

\author{
Handoko $^{1}$, Burhanuddin Tola ${ }^{2}$, Yeti Supriyati ${ }^{3}$, Itsar Bolo Rangka ${ }^{4}$ \\ \{handokoalex2012@gmail.com ${ }^{1}$, burhanuddin.tola@gmail.com², y_supriyati@yahoo.com ${ }^{3}$, \\ itsar@konselor.org $\left.{ }^{4}\right\}$ \\ Universitas Negeri Jakarta, Jakarta, Indonesia ${ }^{1,2,3}$ \\ Universitas Indraprasta PGRI, Jakarta, Indonesia ${ }^{4}$
}

\begin{abstract}
National exam is an educational analysis, nationally conducted to measure and evaluate students' academic competence in various levels of education (primary, secondary l, vocational and senior high school). The benchmark of success analyzed from the students' result during the education phase through nationally conducted exam organized by the government the Education and Culture Ministries. The change in exam method from manual (by paper) to a computer-based exam is an ideal solution for a brighter and more technological education system. The development of human resources with respect to the exam organizers becomes one of the significant factors that lead to the inception of the computer-based exam. Adequate information and technology system is to be owned by schools that organize computer-based exam. Some of the advantages associated with the change from manual-based exam to computer-based are: exams questions and answers cannot be leaked, fast checking system, and students get to see their results earlier.
\end{abstract}

Keywords: semi-online, manual exam, computer-based test.

\section{Introduction}

The education system of a nation plays a significant role in the success of its human resources, improvement, and development of a nation. The success of a country's education is seen from the achievement of its national examination results organized by the educational institutions, either at elementary, junior high or high school levels. National examination is carried out at least once in every educational level. Formal and informal education must be the priority of every nation to produce citizens with good character traits and personality not underestimated by other nations. A country without a standard education system fails to possess precise directions and goals. The quality of education in a country determines the level of its community's life. A lower education level will bring a negative impact on the progress of a nation. It is believed that many crimes occur owing to the low level of communities' education.

The advancement in information technology has led to the elimination of manual examination system and the introduction of a computerized system by the national examination. A computer-based exam system is a carried out online using the computer. The aim of implementing a computer-based examination is not different from its paper-based counterpart which is to ascertain students learning process at a certain level. The new method is applied to simplify the distribution of examination materials, save money on printing, shipping, and security, to avoid leakages. It also shortens the required time used to process and mark student's 
text scripts. The implementation of the computer-based examination system is conducted in collaboration with various parties, including universities spread across multiple regions in Indonesia.

\section{Literature Review}

Students' academic performance is dependent on their feedback, which aids for a better learning process. The reflection needs to be evaluated to get a positive impact both for teachers and students, thereby, giving room for improvement. [1]. The results obtained are used to decide if the ongoing program should be continued, stopped, or revised. This technique aims at eliminating inconsistencies with minimal errors. Changing from paper-based to computer-based examination requires proper analyses to obtain perfect results.

An examination is a way used to ascertain students' skill level during the learning process. The application of Information Technology and Communication in the examination could increase the efficiency and decrease the time needed for students to get notifications on their scores after the exam. This will ensure that students are properly evaluated. The online system has proven its merits associated with managing the test system appropriately [2]. The examination system which was formerly conducted manually is also known as Traditional Examination. [3]. The implementation of paper-based examination requires printing examination texts and answer sheets used by students, which has been proven to being a less efficient technique. The various inconsistencies associated with this method include poor handling of the paper script, difficulty in maintaining adequate distribution and publishing the results. Furthermore, this technique leads to loss of question papers and answer sheets. In line with those possibilities, a paper-based examination is associated with numerous setbacks [4].

Computer Based Test (CBT) is defined as the computerized system of managing examinations online. CBT provides students with test items that they can answer directly on the computer. By using this system, students' achievement on the exam can be well evaluated quickly [5]. It distributes examinations results to students automatically without delay. An online examination system or computer-based examination is a testing system that allows users to update questions dynamically, without coming across the paper beforehand.

Minimizing examination inconsistencies can increase its success. Identifying possible obstacles, preventing and anticipating concrete steps must be taken by the examiners. It is expected that computer-based examination will become an ideal solution for the national evaluation of students with minimal errors and $\mathrm{y}$ accurate results. Due to technology advancement and more benefits offered in CBT, this test system has taken a role of the PBT in many aspects, such as time flexibility, fast responses, and schedule effectiveness. It is found that CBT does not affect the students' performance, scores, and variables [6]. There are several advantages associated with computer-based examination compared to manual examination (paper-based examination). For instance, CBT eliminates the use of pen and paper, the leakage of exam questions, and the timeframe required to output results.

\section{Method}

\subsection{Participant}


The purposive, a non-probability sampling technique was used to collect sample data from 4 schools located in SMA region ( 2 from SMK and 1 from MAN) all in Jakarta. The respondents of this research are principal, technician, proctor, students and central coordinator of the computer-based national exam, Education Assessment Center (Puspendik), the Ministry of Education and Culture. Each respondent knows about the research objective, that is, to increase the improvements in the implementation of a computer-based national exam in the forthcoming years.

\subsection{Procedures}

Kirkpatrick's evaluation model was used to analyze and evaluate the obtained data. By ensuring the training is executed as expected. In addition to that, the CIPP evaluation model developed by Daniel Stufflebeam was used to examine and evaluate the system. Those two evaluation models are integrated into a research combination model to produce an outstanding CBT system. As the evaluation model advances, Kirkpatrick introduces the new version named The New World Kirkpatrick Model (NWKM), that meets conformity to the context-inputprocess-product (CIPP) model [7].

Evaluation is a way to identify the strengths and weaknesses of projects, programs or organizations. Such models and designs are proposed and incorporated into the CIPP model used for curriculum analysis. The model developed by Stufflebeam in 1983 is subdivided into four parts, namely: C-Context, I-Input, P-Process and P-Product [1]. CIPP Model is appropriately used to examine the implementation of computer-based national examination by considering each view component.

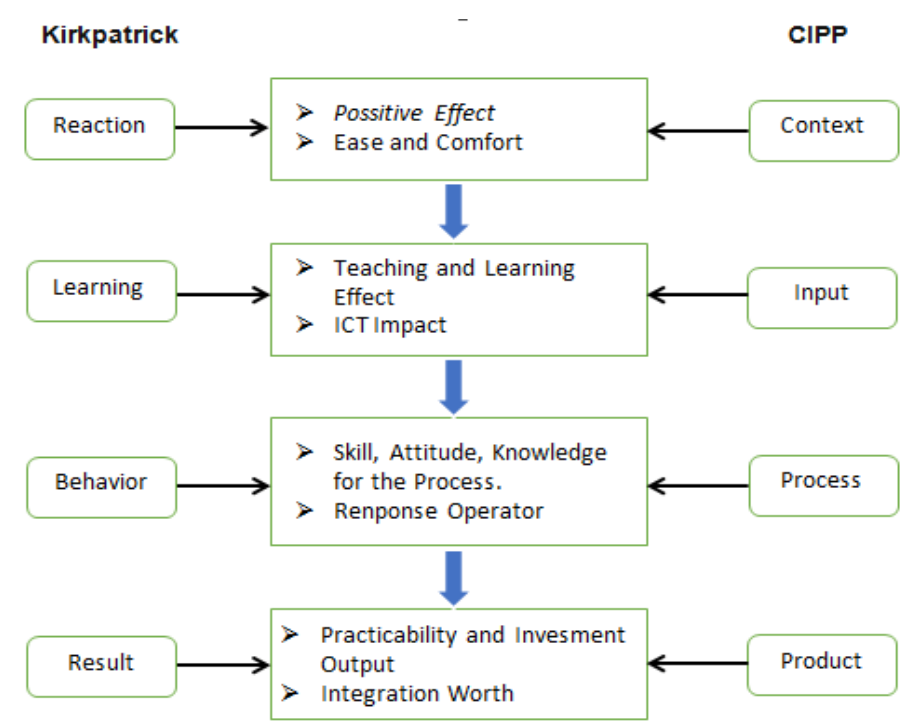

Fig 1. Conceptual framework. 


\section{Data Analysis}

The data analysis in this research is categorized in 3 phases, that is, before entering the field, inside the filed, and after completion. Before joining the field, the researcher has already had an overview of the research objective as well as the things that need to be researched. The analysis is conducted on the introduction, and background or secondary data which will be used to determine various research focus. However, the focus of this research is still temporary and will be developed in the field. Moreover, when the researcher is at the field, determining the "key informant" so that the collected data could be developed becomes viable.

The data analysis technique used is the online evaluation research of Miles and Huberman model. Data reduction is defined as a process of changing and processing raw data obtained from various sources during the present research process. Various data are selected and classified based on the benefit, importance, and objective from each research process. The method of data reduction is carried out during the research and after the researcher returns to the field. Using data reduction will ease the process until the analyst draws an appropriate conclusion. This stage is conducted by carrying out important, meaningful, and relevant data grouping with the research objective so that conclusions can be drawn and verified using theme and table. This is done when the data served looks exciting and easy to understand.

\section{Discussion}

ICT is a terminology which comprises all technical equipment used to process and convey information. ICT consists of computer-based information technology and computer communication technology. In the computer-based test implementation, the use of information and communication technology is said to be very important. The readiness of the national exam for ICT is not only about the network, but about how ready schools are ready to carry out reviews using this technique.

The significant number of students who undertake national exam could lead to computer client's error. The ability of proctor handling problems is the primary key that supports these problems. Reflected from disturbance faced by those students, then backup computers must be provided at each room to computer availability if issues arise. In each place, there should be a minimum of 4 backup computers available to 40 students partaking in the test. The availability of the power supply must also be confirmed when the test is implemented. A sudden power outage will disrupt the test and the students might end up losing their answers.

The most critical investment value for every school is the implementation of a computerbased test. If schools are concerned about the inconsistencies associated with paper-based tests, then by the introduction of a computer-based test should resolve it. The computer-based test gives benefits school by providing the unaltered result to students. Those results can be used as a reference for enhancing the school's academic learning process in the future.

Computer-based exam is more comfortable to perform compared to the paper-based exam. Schools are not preoccupied with taking manuscripts about computer answer sheets. The benefit earned by students is easy in undertaking the exam. Students are not preoccupied with circling computer answer sheets or deleting answers if they make a mistake during the test. Students are obliged to click only solutions that are considered correct. If mistakes happened, they could quickly change the answers. 
The distribution of computer answer sheets will increase budget savings. The answer sheets of computer checking which is usually conducted by scanning will automatically disappear so that the answers can be directly sent through school operator (proctor) to the central computerbased national exam system (kemendikbud). The results of students' national exam at every school can be acknowledged directly by central government just after the school sends the answers through the proctor (even the school will not have an idea of the results obtained by the students). The dataset can be accessed in https://osf.io/gr9af/ Open Science Framework[8]

\section{Conclusion}

It can be concluded that computer-based national exam is much more economical compared to paper-based test: 1) Students enthusiastically participate in computer-based national exam as it is easier to be implemented than the pen-paper based national exam. 2) It eliminates the process of printing paper-based test, thereby, reducing the use of papers. 3) it prevent the leak of test questions. 4) The distribution of questions and answers sheets becomes easier, 5) The results obtained by students are the original result because there is no leakage of test questions prior to the exam. 6) With the original result obtained by students, then the test result can be used as student's capability mapping, either based on the region or nationally. 7) the school can use it as an evaluation strategy to determine students' achievement, improve school's dignity, and future advancement. 8) Computer-based test requires reliable human resources to be implemented with ICT preparation, (Information, Communication and Technology) which are adequate.

\section{References}

[1] Aziz, Shamsa., Munazza Mahmood, Zahra Rehman: Implementation of CIPP Model for Quality Evaluation at School Level: A Case Study. Journal of Education and Educational Developement. Vol. 5, issue 1, pp. 189-206 (2018)

[2] Kuyoro, S.O., G. U. Maminor, R. U. Kanu, O. Akande: The Design and Implementation of a Computer Based Testing System. Journal of Applied Computation. Vol. 1, No. 1, pp. 1-7 (2016)

[3] Michael Ajinaja: The Design and Implementation of a Computer Based Testing System Using Component-Based Software Engineering. International Journal of Computer Science And Technology. Vol. 8, Issue 1, pp. 58-65 (2017)

[4] Reddy, M. Mani Mohan Reddy, Mahendhra Sahani, dan Lakshmi: Online Exam Management System. International Journal of Engineering Research in Computer Science and Engineering. Vol. 4, Issue 3, pp. 55-58 (2017)

[5] M. O. Onyesolu dan Ezenwegbu Nnamdi Chimaob: Design and implementation of JAMB Computer-Based Test System with Voice Command. International Journal on Recent and Innovation Trends in Computing and Communication. Vol. 5, Issue 6, pp. 540-548 (2017)

[6] Hooshang Khoshsima dan Seyyed Morteza Hashemi Toroujeni: Comparability of Computer-Based Testing and Paper-Based Testing: Testing Mode Effect, Testing Mode Order, Computer Attitudes and Testing Mode preference. International Journal of Computer. Vol. 4, No. 1, pp. $80-99$ (2017)

[7] Moreau, Katherine A.: Has the new Kirkpatrick generation built a better hammer for our evaluation toolbox?. Med Teach. Vol. 39, No. 9, pp. 999-1001 (2017)

[8] Handoko, "The Change of National Exam System from Paper-Based Test into Computer-Based Test,” 06-Jan-2019. [Online]. Available: osf.io/gr9af. 